\title{
Experiencias didácticas para la incorporación de la perspectiva de género desde la cátedra Geografía Económica y Política General
}

\author{
Mgtr. Vilma Lilian Falcón \\ Profesora Titular. Cátedra Geografía Económica y Política General \\ vfalcon1609@hotmail.com \\ Trabajo presentado como Panelista en la jornada

\section{"Hacia una educación superior con inclusión de género"} \\ Jornada Hacia una Educación Superior con inclusión de género. Centro de Investigación y Estudios de \\ Género. Facultad de Humanidades- UNNE. Resistencia, 11 de abril de 2013.
}

Resumen

Nuestra cátedra, Geografía Económica y Política General, corresponde al Plan de Estudio del Profesorado y Licenciatura en Geografía de la Facultad de Humanidades de la Universidad Nacional del Nordeste (UNNE). Se trata de una materia con amplias posibilidades de incorporar la perspectiva de género en algunos de sus temas. La cursan alumnos del tercer nivel de la carrera y se ofrece como optativa para los alumnos de Historia. Este dato no es menor ya que los alumnos de ambas disciplina tienen una trayectoria interesante y han cursado materias que en los últimos años, en sus contenidos, directa o indirectamente, comenzaron a plantear algunos temas relacionados con el enfoque de género. Esto es muy importante porque constituyen espacios de reflexión para el alumno y un ámbito propicio que llevan a reconsiderar y resignificar conceptos, categorías y escalas de análisis y especialmente llevan a la revisión de los principios teóricos y metodológicos que pueden derivar en una nueva manera de investigar y trabajar temas que figuran en los programas pero que se pueden realizar a partir de una mirada de género.

Siguiendo lo expresado por Marta Lamas (2004), también estoy convencida que incorporar la perspectiva de género a nuestra disciplina no se trata solo de agregar ciertos temas en los programas o contenidos que enseñamos o investigamos; se trata de sacar a la luz, a través de verdaderas discusiones teóricas, temas hasta ahora ignorados u ocultos que permitan interpretar fenómenos que hasta el momento fueron insuficientemente explicados desde nuestra ciencia y que reflejen ese "salto conceptual" al que la autora nos invita a realizar cuando nos señala que la teoría no es un lujo sino una necesidad " no solo para facilitar el indispensable cambio de

Publicado en formato digital: Mgtr. Vilma Lilian Falcón. Experiencias didácticas para la incorporación de la perspectiva de género desde la cátedra Geografía Económica y Política General. Producción en Docencia. Revista Geográfica Digital. IGUNNE. Facultad de Humanidades. UNNE. Año 12. N N 23. Enero - Junio 2015. ISSN 1668-5180 Resistencia, Chaco.

En: http://hum.unne.edu.ar/revistas/geoweb/default.htm 
paradigmas sobre la condición humana, sino para frenar las prácticas discriminatorias que traducen diferencia por desigualdad". (Lamas, M.,2004:2).

En nuestra cátedra, hemos comenzado -modestamente- la búsqueda de reinterpretación de una Geografía que demuestre que el espacio no es neutro desde el punto de vista del género. Desde las clases teóricas, por ejemplo, hemos iniciado una lucha bastante encarnizada con el tema del lenguaje, precisamente porque el término "Hombre" aparece en los libros de textos con absoluta frecuencia. Decir que "El objetivo básico de la Geografía ha sido y es el estudio del espacio así como de las relaciones del hombre con su entorno" es un claro ejemplo en este sentido. No podemos cambiar los textos pero sí creemos necesario advertir al alumnado que al "universalizar el término hombre" u otros frecuentemente "masculinizados", se está invisibilizando a las mujeres.

Como experiencia concreta desarrollamos un Trabajo Práctico que tiene por objetivo: Reflexionar acerca de la intervención de la mujer en el proceso económico y en el desarrollo económico. Contextualizar este trabajo práctico requiere de una presentación teórica, por lo que hemos encontrado un espacio desde el cual abordar a la Geografía del Género, su evolución e implicancias actuales de su desarrollo. Trabajamos con el concepto de Género, re conceptualizamos a los conceptos de: trabajo, tareas productivas, reproductivas, salario, ingresos, incorporamos otras categorías de análisis. Todo ello requiere que el alumno consulte nueva bibliografía, lea diferentes textos y reflexione acerca de este tema.

Por otro lado, en la mayoría de los casos, los prácticos requieren trabajar con estadísticas; en razón de ello hemos incorporado algunas estadísticas de género entendiendo que se trata de una herramienta imprescindible para dar visibilidad a las distintas manifestaciones de las desigualdades de género. Por un lado, se refuerza la idea de que el análisis estadístico no se limite a contrastar las cifras o valores entre hombres y mujeres a través de las fuentes (diferencias en la natalidad, mortalidad, las tasas de paro, el empleo precario...), sino que se constituya en un instrumento que los lleve a reflexionar, analizar, indagar acerca de las causas que provocan esas diferencias y las consecuencias que tienen en la sociedad y sobre el espacio donde ella construye las relaciones.

Publicado en formato digital: Mgtr. Vilma Lilian Falcón. Experiencias didácticas para la incorporación de la perspectiva de género desde la cátedra Geografía Económica y Política General. Producción en Docencia. Revista Geográfica Digital. IGUNNE. Facultad de Humanidades. UNNE. Año 12. N N 23. Enero - Junio 2015. ISSN 1668-5180 Resistencia, Chaco.

En: http://hum.unne.edu.ar/revistas/geoweb/default.htm 
Precisamente, la representación de los datos seleccionados en la cartografía a nivel mundial, regional, nacional y/o provincial permite, siempre que los datos resulten comparables a las distintas escalas, conocer con mayor detalle en qué lugar del territorio se manifiestan diferencias apreciables, bajo qué situaciones particulares se dan, cuáles son los aspectos sobresalientes que marcan las diferencias y fundamentalmente quién o quiénes son y dónde están las personas más vulnerables ya sea que se trate de varones o mujeres- dentro del conjunto de la sociedad. En este sentido, queremos destacar la importancia de la cartografía como una herramienta analítica que puede denunciar situaciones injustas $y$, atendiendo a lo que señala Córdova Ordoñez, acordamos en considerar que "la cartografía no tiene por qué reducirse a ser la mera expresión descriptiva de unos hechos; puede y debe convertirse en un medio para denunciar aspectos que territorialmente se manifiestan desequilibrados, injustos y desiguales (.....), la cartografía nos permite seguir haciéndonos preguntas sobre el espacio en el que desarrollamos nuestra actividad, aquel en el que construimos nuestra propia identidad tanto personal como grupal". (Córdoba Ordoñez -en Gago García,2006)

Publicado en formato digital: Mgtr. Vilma Lilian Falcón. Experiencias didácticas para la incorporación de la perspectiva de género desde la cátedra Geografía Económica y Política General. Producción en Docencia. Revista Geográfica Digital. IGUNNE. Facultad de Humanidades. UNNE. Año 12. No 23. Enero - Junio 2015. ISSN 1668-5180 Resistencia, Chaco.

En: http://hum.unne.edu.ar/revistas/geoweb/default.htm 